\title{
Reduction and Desulphurization of Chromium Ore Pellet Containing Carbonaceous Material in the Flowing Atmosphere of $\mathrm{H}_{2}-\mathrm{CO}^{*}$
}

\author{
By Hiroshi G. KATAYAMA**
}

\begin{abstract}
Synopsis
Chromium ore pellets containing carbonaceous material were reduced at various temperatures between 950 and $1350^{\circ} \mathrm{C}$ in the flowing atmospheres of $\mathrm{H}_{2}-\mathrm{CO}$ with different $\mathrm{H}_{2}$ concentrations. The rate of reduction increases to a large extent with the increase in $\mathrm{H}_{2}$ concentration. In $100 \%$ $\mathrm{H}_{2}$ atmosphere it is much higher than that in any other atmosphere investigated up to date. The kinetic analysis on the basis of a simplified reaction model showed that such promotion of reduction with $\mathrm{H}_{2}$ is mainly due to the decrease in resistance of intraparticle diffusion of gaseous reactants and products through the reduced layer formed around chromite grain. The desulphurization during reduction of the pellet is remarkably promoted by the presence of a relatively low concentration of $\mathrm{H}_{2}$ in furnace atmosphere. It seems that organic sulphur originated from coke is removed in the earlier stage of reduction and at lower temperatures whereas the sulphur removal from inorganic sulphide requires higher temperatures.
\end{abstract}

Key words: carbothermic reduction; desulphurization; chromium ore pellet; effect of furnace atmosphere; kinetic analysis; activation energy.

\section{Introduction}

Recently prereduction process of chromium ore pellet containing carbonaceous material has been developed in Japan, ${ }^{1-3)}$ where the product has been used in an electric arc furnace to produce high carbon ferrochrome, furthermore it being intended as a charge in new production process of ferrochrome and chromium steel by the use of top and bottom blowing converter. ${ }^{4)}$

Fundamental researches ${ }^{5-18)}$ concerning carbothermic reduction of chromium ore have done in thermodynamic aspects, sequence of reduction, compositional and structural changes of chromite grain, effect of the types and the grain sizes of chromium ore and carbonaceous material and so on. However, there were few studies concerning effect of the gaseous composition of furnace atmosphere on the rate of reduction, ${ }^{19)}$ in spite of its great practical importance for improving operation of prereduction furnace. Thus, the authors ${ }^{20}$ ) have conducted the reduction tests of chromium ore pellet containing carbonaceous material in the flowing atmospheres of $\mathrm{N}_{2}-\mathrm{CO}, \mathrm{N}_{2}-$ $\mathrm{CO}-\mathrm{H}_{2}$ and $\mathrm{N}_{2}-\mathrm{CO}-\mathrm{CO}_{2}$. The result showed that the rate of reduction increases with the decrease in the concentration of $\mathrm{CO}$ and with the increase in that of $\mathrm{H}_{2}$ and that low concentration of $\mathrm{CO}_{2}$ remarkably retards the progress of reduction and consumes the coke contained in pellet.

The present study was intended to highlight the promotion of reduction with $\mathrm{H}_{2}$ in atmospheric gas. The pellet was reduced at various temperatures between 950 and $1350^{\circ} \mathrm{G}$ in the flowing atmospheres of $\mathrm{H}_{2}-\mathrm{CO}$ with different $\mathrm{H}_{2}$ concentrations, kinetic analysis being conducted on the basis of an unreacted core model. In addition, experiments were conducted of effect of temperature and the $\mathrm{H}_{2}$ concentration of atmospheric gas on desulphurization during reduction, some discussions on them being attempted.

\section{Experimental}

Ghromium ore pellets containing carbonaceous material produced by Japan Metals and Chemicals Go., Ltd. were used. Their chemical composition is given in Table 1. Before using for reduction experiment, the pellets were ground by a polishing paper to about $0.87 \mathrm{~cm}$ in diameter and were dried at about $110^{\circ} \mathrm{G}$. A busket made from nickel or molybdenum wire of $0.5 \mathrm{~mm}$ in diameter was used as a sample vessel.

As shown in Fig. 1, the reduction apparatus consisted of a thermobalance using a silica spring. The reaction tube was of high alumina and $3 \mathrm{~cm}$ in inner diameter. The tower containing copper powder was maintained at about $250^{\circ} \mathrm{G}$ for $\mathrm{O}_{2}$ removal from GO.

When the furnace temperature was elevated to the required level, the pellet was suspended at the lower part of glass tube, the tube being closely connected to the reaction tube. The $\mathrm{H}_{2}-\mathrm{CO}$ mixture with the required $\mathrm{H}_{2}$ concentration was flowed through the reaction tube at the total flow rate of $400 \mathrm{Ncc} / \mathrm{min}$. When the pellet was lowered along the axis of the tube, it was preheated first for $3 \mathrm{~min}$ at the place corresponding to $800 \sim 900^{\circ} \mathrm{C}$ and next for 2 min at the highest temperature zone. Thereafter, elongation readings of silica spring were taken by a cathetometer and were usually continued for $120 \mathrm{~min}$.

The degree of reduction $(R)$ was determined from the following equation:

$$
R(\%)=\left[\frac{\left(L_{t}-L_{e}\right)(W-B)}{L_{e}-L_{0}}+B-B^{\prime}\right] \frac{100}{A}
$$

where, $L_{0}, L_{t}, L_{e}$ : elongation readings of silica spring at the beginning, at a given time and at the end of measurement, respectively

$W, B$ : weight losses of the pellet after the end of measurement and pre-

\footnotetext{
* Based on the paper presented to the 111 th ISIJ Meeting, April 1986, S16, at The University of Tokyo in Tokyo. Manuscript received on January 21, 1987; accepted in the final form on March 13, 1987. (C) 1987 ISIJ

** Department of Metallurgical Engineering, Muroran Institute of Technology, Mizumoto-cho, Muroran 050.
} 
Table 1. Chemical composition of chromium ore pellet containing carbonaceous material. (wt\%)

\begin{tabular}{ccccccc}
\hline $\mathrm{Cr}_{2} \mathrm{O}_{3}$ & $\mathrm{Fe}$ & $\mathrm{SiO}_{2}$ & $\mathrm{Al}_{2} \mathrm{O}_{3}$ & $\mathrm{MgO}$ & $\mathrm{C}$ & $\begin{array}{c}\text { Ig. } \\
\text { loss* }\end{array}$ \\
\hline 37.42 & 10.61 & 7.62 & $\mathbf{8 . 4 8}$ & 11.76 & 14.73 & 3.66 \\
\hline
\end{tabular}

* At $900^{\circ} \mathrm{C}$ under $\mathrm{N}_{2}$ atmosphere.

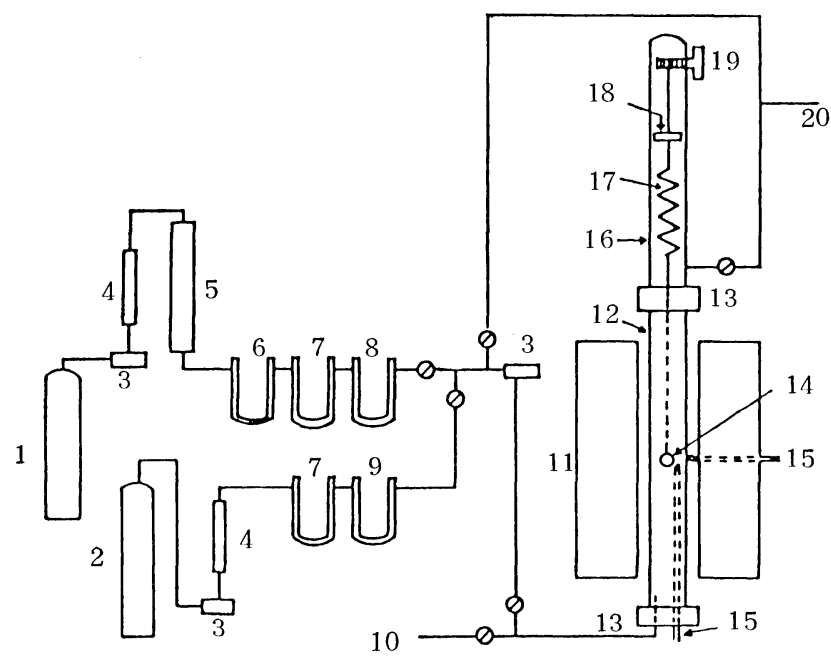

(1) $\mathrm{CO}$ gas

(2) $\mathrm{H}_{2}$ gas

(3) Needle valve

(11) Electric furnace

(4) Flow meter

(12) Reaction tube

(5) Copper powder

(6) $\mathrm{NaOH}$

(7) Silica gel

(8) $\mathrm{P}_{2} \mathrm{O}_{5}$

(9) $\mathrm{Mg}\left(\mathrm{ClO}_{4}\right)_{2}$

(10) To rotary pump

(13) Brass cap

(14) Pellet

(15) $\mathrm{Pt}-\mathrm{Pt} \cdot 13 \% \mathrm{Rh}$ thermocouple

(16) Glass tube

(17) Silica glass spring

(18) Centering ring

(19) Windlass

(20) Gas outlet

Fig. 1. Reduction apparatus.

heating $(\%)$

$B^{\prime}$ : volatile matter content of the pellet $(\%)$

$A$ : weight loss corresponding to the complete reduction of $\mathrm{Cr}$ and $\mathrm{Fe}$ oxides contained in the pellet. It was stoichiometrically calculated in which gaseous product was assumed to be GO only. ${ }^{17,20}$ )

Sulphur content of the pellets reduced under various conditions was determined by the method according to JIS. ${ }^{21)}$

\section{Reduction Kinetics}

\section{Results}

Reduction experiments were conducted over the temperature range of 950 to $1350^{\circ} \mathrm{C}$ in the flowing atmospheres of $\mathrm{H}_{2}-\mathrm{CO}$ with different $\mathrm{H}_{2}$ concentrations. Several examples of reduction curves are shown in Figs. 2 to 5.

As shown in the figures, the rate of reduction increases with the increases in temperature and $\mathrm{H}_{2}$ concentration of atmospheric gas. Effect of the $\mathrm{H}_{2}$ concentration on the rate of reduction is more remarked, especially below $1250^{\circ} \mathrm{C}$. For example, the degree of reduction attained after $60 \mathrm{~min}$ at $1100^{\circ} \mathrm{C}$ is only about $8 \%$ in $\mathrm{CO}$ atmosphere, whereas it reaches much higher level of $52 \%$ in $90 \% \mathrm{H}_{2}-$ $10 \% \mathrm{CO}$ atmosphere. The reduction does not complete even after $120 \mathrm{~min}$ at $1350^{\circ} \mathrm{G}$ with $\mathrm{CO}$ and $60 \% \mathrm{H}_{2}-40 \% \mathrm{CO}$ mixtures, whereas with $90 \% \mathrm{H}_{2}-$ $10 \% \mathrm{CO}$ mixture it reaches to completion of reduction in about $60 \mathrm{~min}$ at the same temperature. The rate of reduction in $\mathrm{H}_{2}$ atmosphere is much higher than that in any other atmosphere. The degree of reduction of more than $100 \%$ observed at the later stage of reduction at $1200^{\circ} \mathrm{C}$ or above is considered to be due to the contribution of reduction of other oxides such as $\mathrm{SiO}_{2}$.

In order to examine the effect of $\mathrm{H}_{2}$ concentration in more detail, the degrees of reduction attained after different durations of reduction at $1200^{\circ} \mathrm{G}$ were plotted against the $\mathrm{H}_{2}$ concentration in Fig. 6. It is found that the promoting effect with $\mathrm{H}_{2}$ is remarkably large, especially in the ranges of $\mathrm{H}_{2}$ concentration below $10 \%$ and above $95 \%$.

\section{Mainly Rate-determining Process and Applied Kinetic Equation}

The reduction of chromium ore-carbon pellet involves the simultaneous progress of gaseous reduction of chromite grain and the Boudouard reaction. In addition, it involves the evolution of gaseous product mainly consisted of $\mathrm{CO}$ from the pellet into furnace atmosphere. Therefore, it may be ratedetermined by the following processes:

(1) Gas transfer between the surface of pellet and bulk gas.

(2) Gas transfer through the pores present in pellet.

(3) Gaseous reduction of chromite grain, including intraparticle diffusion of gaseous reactants and products, solid diffusion and interfacial chemical reaction.

(4) Reaction of carbon grain with $\mathrm{CO}_{2}$ and $\mathrm{H}_{2} \mathrm{O}$, including intraparticle diffusion of gaseous reactants and products and surface chemical reaction.

Of the above processes, the resistances of processes (1) and (2) may be neglected because it was observed in the previous study ${ }^{20}$ ) that the rate of reduction is almost independent of the flow rate of atmospheric gas and pellet diameter. Furthermore, it was also found that the resistance of process (3) is much larger than that of process (4). ${ }^{20,22,23)}$ Therefore, the process (3) was considered to be mainly rate-determining process in the reduction of chromium ore pellet containing carbonaceous material, so that kinetic analysis was conducted on this basis.

Since the reduction of chromite grain proceeds topochemically from the surface to the inside, ${ }^{18)}$ its rate may be described by the unreacted core model. According to this model, several kinetic equations including the resistances of various processes have been offered up to date. ${ }^{24)}$ Here the kinetic analysis was conducted by the kinetic equation which includes the resistances of intraparticle diffusion and interfacial 


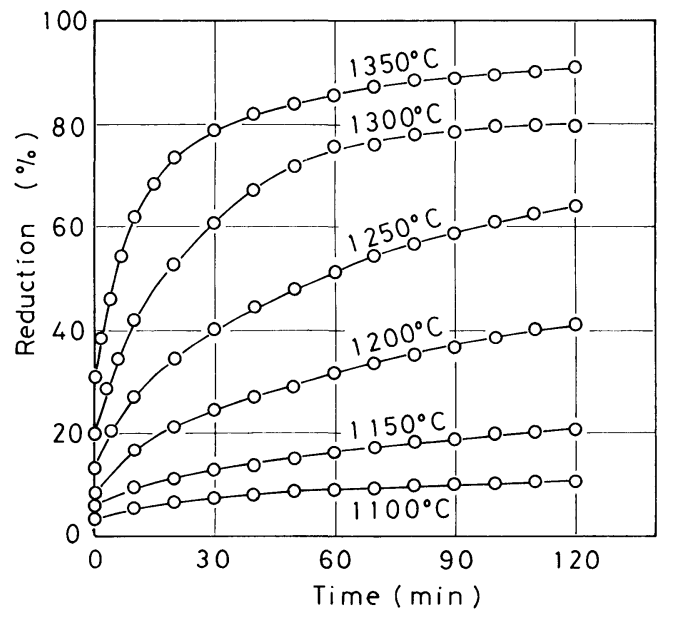

Fig. 2. Reduction curves at different temperatures in the flowing atmosphere of CO.

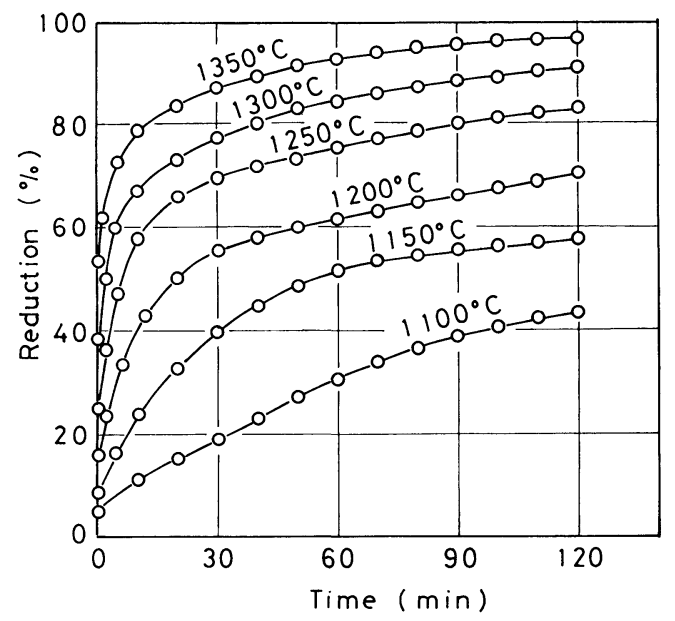

Fig. 3. Reduction curves at different temperatures in the flowing atmosphere of $60 \% \mathrm{H}_{2}-40 \% \mathrm{CO}$.

chemical reaction. The equation is given below ${ }^{24)}$ :

$$
\begin{aligned}
t= & \frac{r_{0}^{2} d_{0}}{6 D_{e}\left(C-C_{0}\right)}\left[3-2 R-3(1-R)^{2 / 3}\right] \\
& +\frac{r_{0} d_{0} K}{k_{r}(1+K)\left(C-C_{0}\right)}\left[1-(1-R)^{1 / 3}\right]
\end{aligned}
$$

where, $\quad t:$ reduction time $(\mathrm{s})$

$r_{0}:$ radius of unreacted chromite grain $(\mathrm{cm})$

$d_{0}$ : reducible oxygen concentration of chromite grain $\left(\mathrm{mol} / \mathrm{cm}^{3}\right)$

$C, C_{0}$ : concentration of reducing gas at the surface of chromite grain and at the equilibrium stage $\left(\mathrm{mol} / \mathrm{cm}^{3}\right)$

$D_{e}$ : intraparticle effective diffusivity $\left(\mathrm{cm}^{2} / \mathrm{s}\right)$

$k_{r}:$ rate constant of chemical reaction $(\mathrm{cm} / \mathrm{s})$

$K$ : equilibrium constant (-).

Since the first and second terms in the right-hand side of Eq. (2) correspond to the times $\left(t_{D}\right.$ and $\left.t_{k}\right)$

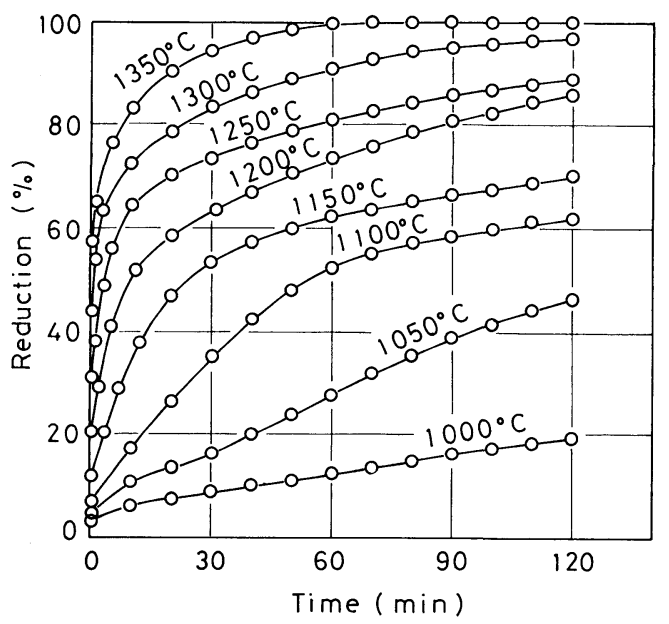

Fig. 4. Reduction curves at different temperatures in the flowing atmosphere of $90 \% \mathrm{H}_{2}-10 \% \mathrm{CO}$.

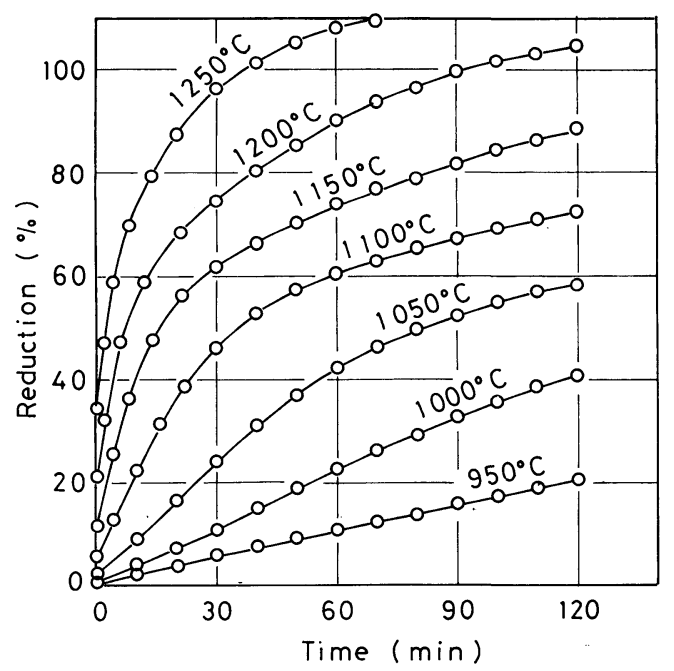

Fig. 5. Reduction curves at different temperatures in the flowing atmosphere of $\mathrm{H}_{2}$.

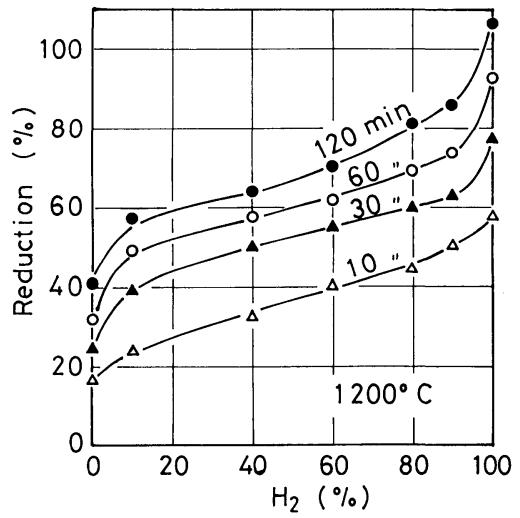

Fig. 6. Effect of the $\mathrm{H}_{2}$ concentration of atmospheric gas on the degree of reduction attained after different duration of reduction at $1200^{\circ} \mathrm{C}$.

which are taken by the resistances of intraparticle diffusion and interfacial chemical reaction, respectively, the overall reduction time $(t)$ is expressed by the following equation: 


$$
t=t_{D}+t_{k}
$$

Dividing the both sides of Eq. (2) by $\left[1-(1-R)^{1 / 3}\right]$, the following equation is derived:

$$
t / F=A\left(3 F-2 F^{2}\right)+B
$$

where, $F=1-(1-R)^{1 / 3}$

$$
\begin{aligned}
& A=r_{0}^{2} d_{0} / 6 D_{e}\left(C-C_{0}\right) \\
& B=r_{0} d_{0} K / k_{r}(1+K)\left(C-C_{0}\right) .
\end{aligned}
$$

It has been found that the spinel components of chromite mineral contained in chromium ore is reduced roughly in the sequence $\mathrm{Fe}_{3} \mathrm{O}_{4} \rightarrow \mathrm{FeCr}_{2} \mathrm{O}_{4}$ $\rightarrow \mathrm{MgCr}_{2} \mathrm{O}_{4} \cdot{ }^{15,17)}$ Since the $\mathrm{Fe}_{3} \mathrm{O}_{4}$ component was little contained in the pellet investigated, the kinetic analysis was conducted concerning the reduction stage of $\mathrm{FeCr}_{2} \mathrm{O}_{4}$ component, in which the degrees of reduction to be used were determined by the division of the observed values of $R$ by the degree of reduction corresponding to complete reduction of $\mathrm{FeCr}_{2} \mathrm{O}_{4}$ component.

\section{Results of Kinetic Analysis and Discussion}

Figures 7 and 8 illustrate the plots of $t / F$ against $\left(3 F-2 F^{2}\right)$ according to Eq. (4). At a temperature of $1150^{\circ} \mathrm{C}$ or above, good linear relationship between them holds except for the later stage of reduction of $\mathrm{FeCr}_{2} \mathrm{O}_{4}$ component in which the contribution of solid diffusion is necessary to be taken into account. At a temperature of $1100^{\circ} \mathrm{C}$ or below, however, the rate of reduction does not obey the above kinetic equation in any atmosphere investigated. This seems to be due to the fact that the reduction of $\mathrm{FeO}$ preceded that of $\mathrm{Cr}_{2} \mathrm{O}_{3}$ in the reduction stage of $\mathrm{FeGr}_{2} \mathrm{O}_{4}$ component, because $\mathrm{Cr}_{2} \mathrm{O}_{3}$ is hard to be reduced below $1100^{\circ} \mathrm{C}^{16,17)}$ As shown in Fig. 7, the line from regression of plots of $t / F$ against $\left(3 F-2 F^{2}\right)$ concerning the data of reduction in $\mathrm{CO}$ atmosphere gives a negative intercept with the ordinate. The reason is probably attributed for the reduction in this atmosphere to be rate-determined only by the intraparticle diffusion of reacting gases through the reduced layer of chromite grain. ${ }^{20)}$

Apparent intraparticle diffusivities $D_{e}^{\prime}(=1 / A)$ and apparent rate constants of interfacial chemical reaction $k_{r}^{\prime}(=1 / B)$ were determined from the slopes and the intercepts of the lines from regression, respectively and were shown in Figs. 9 to 11 as functions of $1 / T$ and the $\mathrm{H}_{2}$ concentration of atmospheric gas, compared with the $D_{e}^{\prime}$ and $k_{r}^{\prime}$ values obtained in the previous study ${ }^{20)}$ where the same pellet was reduced in flowing $\mathrm{N}_{2}-\mathrm{CO}-\mathrm{H}_{2}$ atmospheres. The $k_{r}^{\prime}$ value depends on the total concentration of $\mathrm{H}_{2}$ and $\mathrm{CO}$, but it is independent of the $\mathrm{H}_{2}$ concentration except for reduction in the atmosphere with less than $10 \%$ $\mathrm{H}_{2}$. Temperature dependence of $k_{r}^{\prime}$ is substantially equal to each another, irrespective of the $\mathrm{H}_{2}+\mathrm{CO}$ and $\mathrm{H}_{2}$ concentrations of atmospheric gas. Apparent activation energy of interfacial chemical reaction ranges from 50 to $62 \mathrm{kcal} / \mathrm{mol}$ and is similar to that obtained in the hydrogen reduction of chromic oxide pellet, ${ }^{25)}$ taking account of temperature dependence of the reaction-driving force $\left(C-C_{0}\right)$.

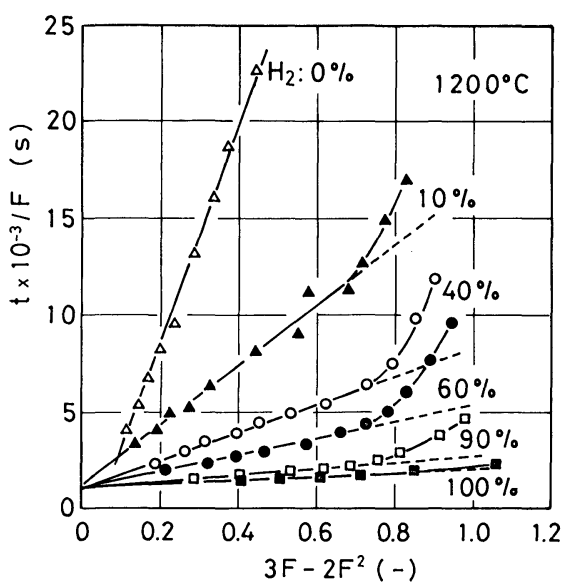

Fig. 7. Plot of $t / F$ against $3 F-2 F^{2}$ for the data obtained at $1200^{\circ} \mathrm{C}$ in the flowing atmospheres of $\mathrm{H}_{2}-\mathrm{CO}$ with different $\mathrm{H}_{2}$ concentrations.

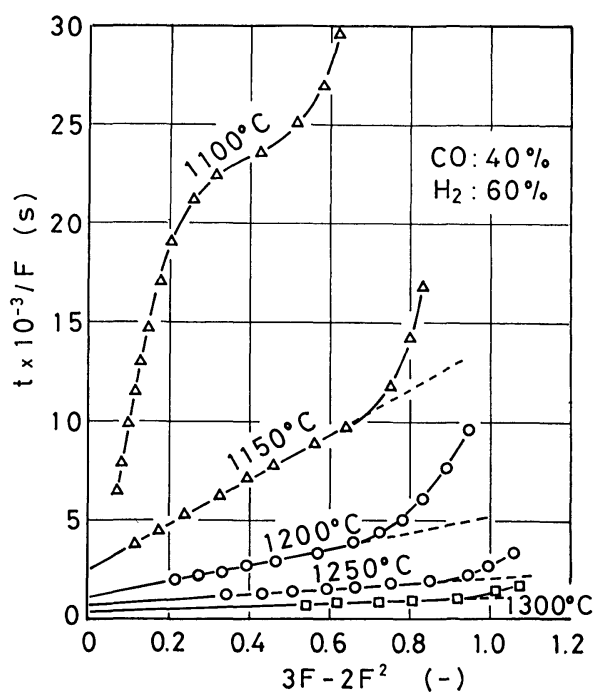

Fig. 8. Plot of $t / F$ against $3 F-2 F^{2}$ for the data obtained at different temperatures in the flowing atmosphere of $60 \% \mathrm{H}_{2}-40 \%$ CO.

The $D_{e}^{\prime}$ values increase with the increase in $\mathrm{H}_{2}$ concentration and its degree of increment is much larger, especially in the concentration range of less than $10 \% \mathrm{H}_{2}$. Temperature dependence of $D_{e}^{\prime}$ decreases with the increase in $\mathrm{H}_{2}$ concentration and hence apparent activation energy of intraparticle diffusion ranges from $51 \mathrm{kcal} / \mathrm{mol}$ for $100 \% \mathrm{H}_{2}$ atmosphere to $120 \mathrm{kcal} / \mathrm{mol}$ for $10 \% \mathrm{H}_{2}$. It is noted that the temperature dependence is much larger than that observed in the gaseous reduction of iron oxide pellet. ${ }^{26)}$ This seems to be due to the fact that the diameter and the fraction of pore formed in reduced layer of chromite grain change to a large extent with increasing temperature. In practice, the same tendency has been also observed in the hydrogen reduction of iron chromite and chromic oxide pellets. ${ }^{25,27)}$

The above results of kinetic analysis showed that the $\mathrm{H}_{2}$ in atmospheric gas promotes to a large extent the intraparticle diffusion of reacting gases but it 


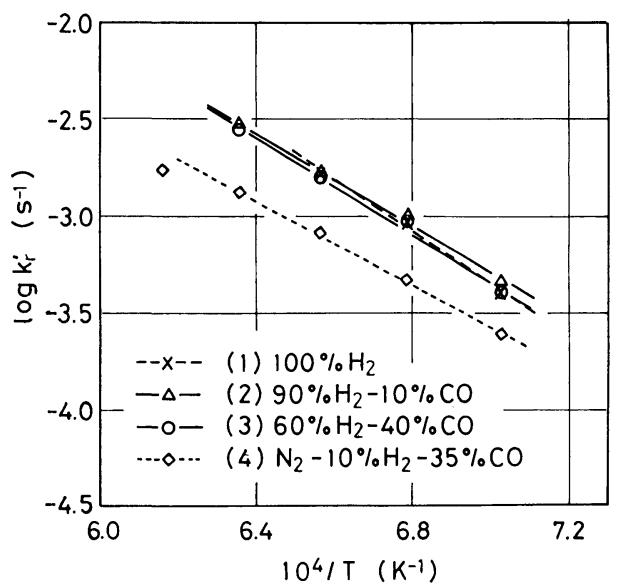

(1) $\log k_{r}^{\prime}=6.140-13560 / T$

(2) $\log k_{r}^{\prime}=5.121-12020 / T$

(3) $\log k_{r}^{\prime}=5.476-12610 / T$

(4) $\log k_{r}^{\prime}=4.054-10890 / T$

Fig. 9. Temperature dependence of $k_{r}^{\prime}$.

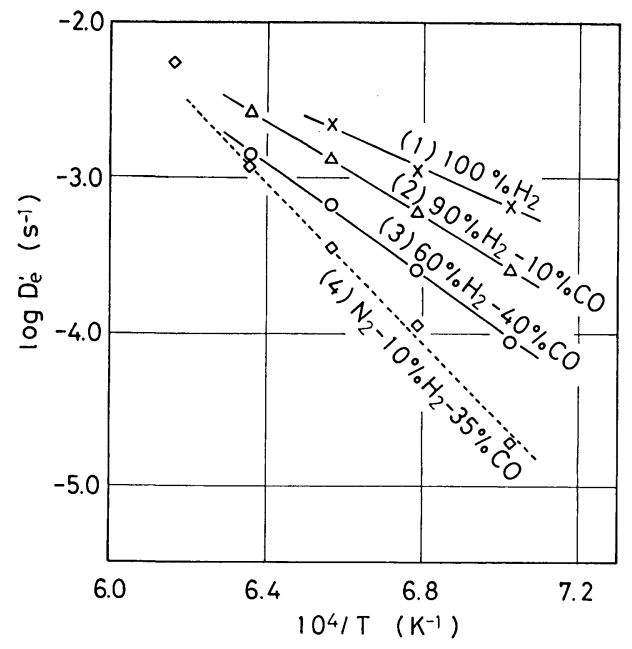

(1) $\log D_{e}^{\prime}=4.649-11160 / T$

(2) $\log D_{e}^{\prime}=7.082-15190 / T$

(3) $\log D_{e}^{\prime}=8.561-17930 / T$

(4) $\log D_{e}^{\prime}=13.830-26320 / T$

Fig. 10. Temperature dependence of $D_{e}^{\prime}$.

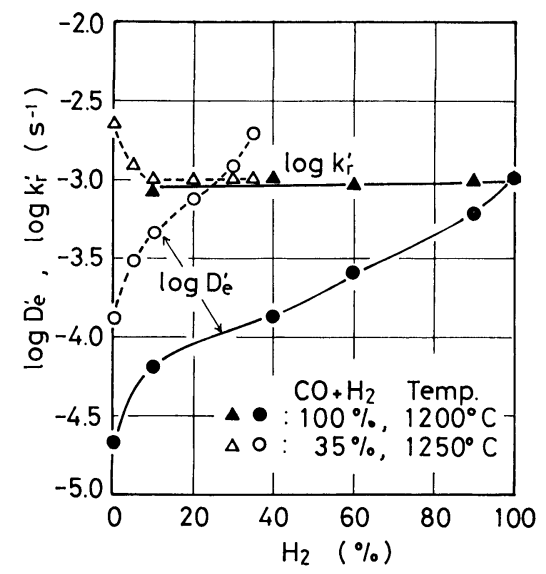

Fig. 11. Effect of the $\mathrm{H}_{2}$ concentration of atmospheric gas on $D_{e}^{\prime}$ and $k_{r}^{\prime}$. has little effect on the interfacial chemical reaction. Since the diffusivity of $\mathrm{H}_{2}-\mathrm{H}_{2} \mathrm{O}$ system is about eight times only as large as that of $\mathrm{CO}-\mathrm{CO}_{2}$ system, the promotion of intraparticle diffusion can not be attributed only to larger diffusivity of $\mathrm{H}_{2}$-containing atmosphere $\left(\mathrm{H}_{2}-\mathrm{CO}-\mathrm{H}_{2} \mathrm{O}-\mathrm{CO}_{2}\right)$, especially in lower $\mathrm{H}_{2}$ concentration and it is necessary to take any other effect into account. One of such effect is considered as shortening of the actual distance where $\mathrm{CO}$ and $\mathrm{CO}_{2}$ diffuse mutually, owing to the progress of the reaction $\mathrm{H}_{2} \mathrm{O}+\mathrm{CO}=\mathrm{H}_{2}+\mathrm{CO}_{2}$ in the reduced layer of chromite grain. ${ }^{28)}$

As mentioned earlier, solid diffusion in the interior of chromite grain contributes to a large extent to the overall reduction in the later stage of reduction of $\mathrm{FeCr}_{2} \mathrm{O}_{4}$ component. From analogy with this tendency, it is concluded that the reduction of $\mathrm{MgCr}_{2} \mathrm{O}_{4}$ component is mainly rate-determined by the solid diffusion.

\section{Desulphurization Behavior}

\section{Results}

Sulphur content of the pellets reduced under various conditions was determined and the degree of desulphurization was calculated from the following equation:

$$
D_{\mathrm{S}}=100(\% \mathrm{~S})_{t}(1-f) /(\% \mathrm{~S})_{0}
$$

where, $(\% \mathrm{~S})_{t},(\% \mathrm{~S})_{0}$ : sulphur contents of reduced and unreduced pellets, respectively

$f$ : fractional loss in weight (-).

Figure 12 shows the changes in sulphur content and the degree of desulphurization during the reduction at 1200 and $1300^{\circ} \mathrm{G}$ in the flowing atmosphere of $20 \% \mathrm{H}_{2}-80 \% \mathrm{CO}$. The desulphurization proceeds at a higher velosity in the early stage of reduction and the degree of desulphurization of more than $80 \%$ is attained after $40 \mathrm{~min}$ at $1200^{\circ} \mathrm{G}$ and after $10 \mathrm{~min}$ at $1300^{\circ} \mathrm{C}$.

Figure 13 shows the effects of temperature and the $\mathrm{H}_{2}$ concentration of atmospheric gas on the sulphur content and the degree of desulphurization. The sulphur content decreases in two steps below $1150^{\circ} \mathrm{C}$ and between 1200 and $1250^{\circ} \mathrm{G}$ or 1250 and $1300^{\circ} \mathrm{C}$ and there is the corresponding stepwise increase in the degree of desulphurization. The desulphurization is remarkably promoted by the $\mathrm{H}_{2}$ in atmospheric gas, especially in the concentration range of less than $20 \% \mathrm{H}_{2}$.

\section{Discussion}

The promotion of desulphurization with $\mathrm{H}_{2}$ may be attributed to the fact that the reaction $\mathrm{H}_{2}+(\mathrm{S})=$ $\mathrm{H}_{2} \mathrm{~S}$ proceeds in preference to the reaction $\mathrm{CO}+(\mathrm{S})=$ GOS from a thermodynamic viewpoint. Figure 14 shows the relationship between equilibrium $P_{\mathrm{H}_{2} \mathrm{~S}} /$ $\left(P_{\mathrm{H}_{2} \mathrm{~S}}+P_{\mathrm{COS}}\right)$ ratio and the $\mathrm{H}_{2}$ concentration of atmospheric gas, providing that only $\mathrm{H}_{2} \mathrm{~S}$ and $\mathrm{COS}$ are produced as gaseous products containing sulphur. 


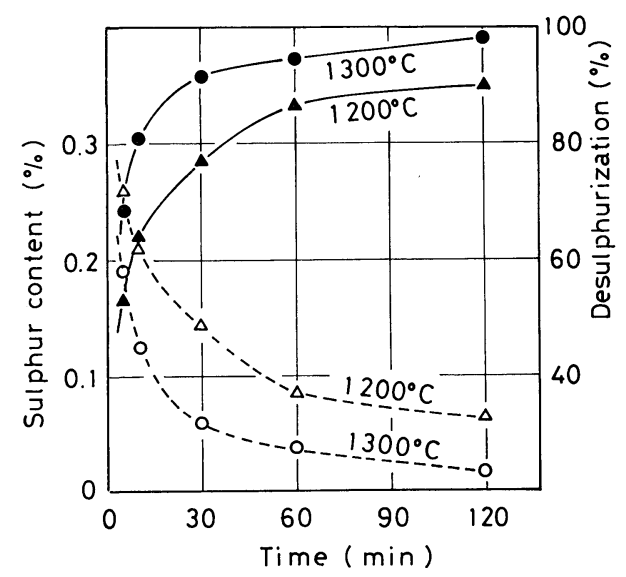

Fig. 12. Desulphurization curves at 1200 and $1300^{\circ} \mathrm{C}$ in the flowing atmosphere of $20 \% \mathrm{H}_{2}-80 \% \mathrm{CO}$.

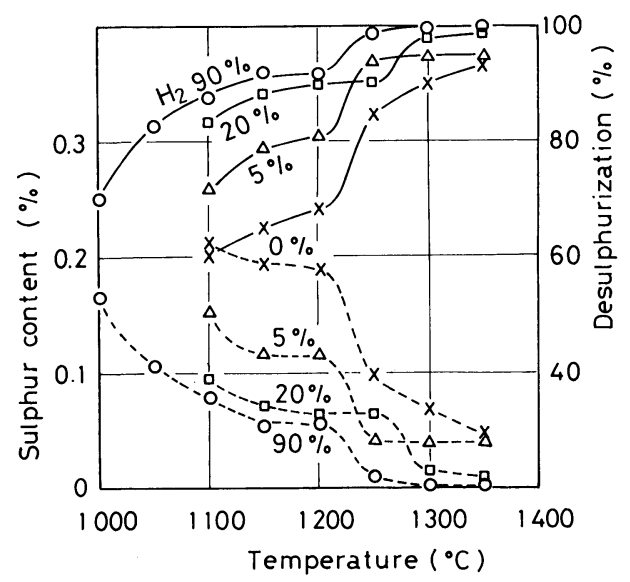

Fig. 13. Effect of temperature and the $\mathrm{H}_{2}$ concentration of atmospheric gas on sulphur content and the degree of desulphurization (reduction time: $120 \mathrm{~min}$ ).

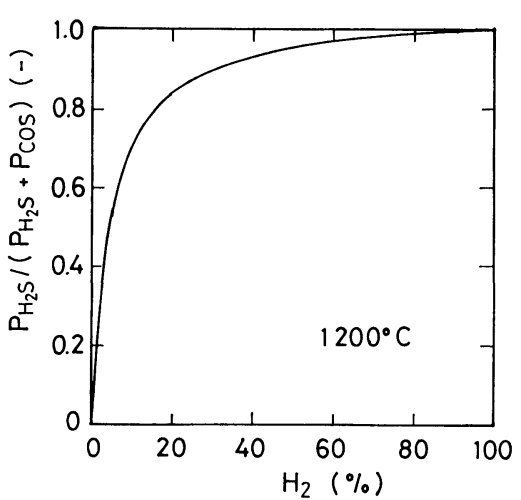

Fig. 14. Relationship between equilibrium $P_{\mathrm{H}_{2} \mathrm{~S}} /\left(P_{\mathrm{H}_{2} \mathrm{~S}}+\right.$ $\left.P_{\mathrm{COS}}\right)$ and the $\mathrm{H}_{2}$ concentration of atmospheric gas.

The equilibrium ratio increases with the increase in the $\mathrm{H}_{2}$ concentration, and it amounts to more than $80 \%$ at $20 \% \mathrm{H}_{2}$. This makes clear for a relatively low concentration of $\mathrm{H}_{2}$ to promote the desulphurization.

Sulphur contained in the pellet originates mainly from coke, in which most of sulphur is present as organic sulphur compound dissolved in carbon and inorganic sulphide such as $\mathrm{FeS}$ and CaS. ${ }^{29)}$ According to Neuhaus et al. ${ }^{30}$ ) the former ranges from 66 to $80 \%$ of total sulphur content and is more easily removed than the latter.

From the consideration of the present result on the basis of the above information, it is concluded that the organic sulphur was removed in the early stage of reduction and at a lower temperature and that the sulphur removal from inorganic sulphide took place above $1200^{\circ} \mathrm{C}$ but in the $\mathrm{H}_{2}$-containing atmosphere it did to a considerable extent even below $1200^{\circ} \mathrm{C}$.

\section{Conclusion}

The reduction rate of chromium ore pellet containing carbonaceous material increases to a large extent with the increase in $\mathrm{H}_{2}$ concentration of furnace atmosphere. In $100 \% \mathrm{H}_{2}$ atmosphere it is much higher than that in any other atmosphere investigated up to date.

The data were analyzed by the use of the kinetic equation which includes the resistances of intraparticle diffusion of reacting gas and interfacial chemical reaction, providing that the reduction of $\mathrm{FeCr}_{2} \mathrm{O}_{4}$ component is mainly rate-determined by the gaseous reduction of chromite grain among various processes involved. The resistance of interfacial chemical reaction depends on the total concentration of $\mathrm{H}_{2}$ and $\mathrm{CO}$ but it is almost independent of the $\mathrm{H}_{2}$ concentration. On the contrary, the resistance of intraparticle diffusion decreases remarkably with the increase in $\mathrm{H}_{2}$ concentration. As a result, it is concluded that the promotion of reduction with $\mathrm{H}_{2}$ is mainly due to the decrease in resistance of intraparticle diffusion of gaseous reactants and products through the reduced layer formed around chromite grain.

The desulphurization during reduction of the pellet is remarkably promoted by the presence of a relatively low concentration of $\mathrm{H}_{2}$ in furnace atmosphere. It seems that organic sulphur originated from coke is removed in the earlier stage of reduction and at lower temperatures whereas the sulphur removal from inorganic sulphide requires higher temperatures.

\section{Acknowledgement}

The author is grateful to Dr. M. Tokuda, Professor of Research Institute of Mineral Dressing and Metallurgy, Tohoku University, for his continuing encouragement and valuable discussion.

\section{REFERENCES}

1) K. Ichikawa, S. Ozawa, K. Ushiyama and M. Yamanaka: Nisshin Steel Tech. Rep., (1972), No. 26, 78.

2) T. Ohta, H. Haga, K. Sugita, T. Toyota, K. Sasaki and N. Moritama: Tetsu-to-Hagané, 61 (1975), S41.

3) S. Yoneka, K. Sugita, Y. Kimura, T. Furui and M. Fukuda: Tetsu-to-Hagané, 61 (1975), S40.

4) H. Kajioka, H. Ishikawa, H. Katayama, M. Kuwahara and M. Fujita: Trans. Iron Steel Inst. Jpn., 26 (1986), B192. 
5) A. N. Morozov, S. S. Lisnyak and A. M. Belikov: Stal in Eng., (1963), 119.

6) W. L. Hunter and D. L. Paulson: U.S. Bur. Mines, Rep. Invest. 6755 (1966).

7) N. A. Barcza, P. R. Jochens and D. D. Howat: Electr. Furn., Conf. Proc., 29 (1971), 88.

8) L. B. McRae and F. K. Siebrits: Nat. Inst. for Metall., Rep. No. 1724 (1975), South Africa.

9) N. L. Woollacott and J. B. See: Nat. Inst. for Metall., Rep. No. 1950 (1978), South Africa.

10) R. H. Nafziger, J. E. Tress and J. I. Paige: Metall. Trans. $B, 10 B$ (1979), 5 .

11) V. Ya. Belogurov, L. M. Izrailev, V. S. Kudryavtsev, V. V. Ponomarenko and S. A. Pchelkin: Steel in USSR, (1972), 511.

12) V. S. Kudryavtsev, L. P. Kostenenko, L. F. Shchugareva, V. Ya. Belogurov and L. L. Zav'yalova: Russian Metall., (1975), No. 6, 5.

13) W. J. Rankin: Trans. Inst. Min. Metall., Sec. C, 88 (1979), Ci107.

14) W. J. Rankin: Arch. Eisenhüttenwes., 50 (1979), 373.

15) H. G. Katayama and A. Tanaka: Tetsu-to-Hagané, 60 (1974), 1289.

16) H. G. Katayama: Bull. Jpn. Inst. Met., 16 (1977), 851.
17) H. G. Katayama and M. Tokuda: Trans. Iron Steel Inst. Jpn., 20 (1980), 154.

18) H. G. Katayama, M. Tokuda and M. Ohtani: Tetsu-toHagané, 70 (1984), 1559.

19) H. G. Katayama: Tetsu-to-Hagané, 63 (1977), 207.

20) H. G. Katayama and M. Tokuda: Tetsu-to-Hagané, 71 (1985), 1607.

21) Japanese Industrial Standard, JIS G1215 (1982).

22) H. G. Katayama and M. Tokuda: Tetsu-to-Hagané, 71 (1985), 1094.

23) H. G. Katayama, M. Tokuda and M. Ohtani: Tetsu-toHagané, 72 (1986), 1513.

24) M. Tokuda, H. Yoshikoshi and M. Ohtani: Trans. Iron Steel Inst. Jpn., 13 (1973), 350.

25) H. G. Katayama: J. Jpn Inst. Met., 50 (1986), 993.

26) Y. Hara, M. Tsuchiya and S. Kondo: Tetsu-to-Hagané, 55 (1969), 1297.

27) H. G. Katayama: Tetsu-to-Hagané, 72 (1986), 396.

28) V. Croft: Metall. Trans. B, 10B (1979), 121.

29) Iron and Steel Handbook, II: Ironmaking and Steelmaking, 3rd ed., ed. by ISIJ, Maruzen, Tokyo, (1979), 203.

30) H. Neuhaus, H. J. Langhammer, H. G. Geck and H. Schenck: Arch. Eisenhüttenwes., 37 (1966), 1. 